\title{
Isparta İli İçin Farklı Çatı Tiplerinde Tasarlanan Fotovoltaik Sistemlerin Karşılaştırılması
}

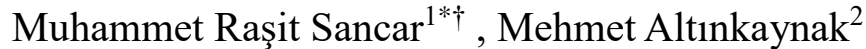 \\ 1* Isparta Uygulamalı Bilimler Üniversitesi, Teknoloji Fakültesi, Enerji Sistemleri Mühendisliği Bölümü, Isparta, Türkiye, (ORCID: 0000-0002-4488-8393), \\ d1840640001@isparta.edu.tr \\ 2 Isparta Uygulamalı Bilimler Üniversitesi, Teknoloji Fakültesi, Makine Mühendisliği Bölümü, Isparta, Türkiye (ORCID: 0000-0003-2434-576X), \\ mehmetaltinkaynak@isparta.edu.tr
}

(Uluslararası Araştırma-Geliştirme ve Tasarım Konferansı - 15-18 Aralık 2021)

(DOI: 10.31590/ejosat.1047453)

ATIF/REFERENCE: Sancar, M.R., Altınkaynak, M., (2021). Isparta İli İçin Farklı Çatı Tiplerinde Tasarlanan Fotovoltaik Sistemlerin Karşılaştırılması. Avrupa Bilim ve Teknoloji Dergisi, (32), 1024-1028.

\begin{abstract}
Özet
Küresel ısınma sebebiyle, elektrik üretiminde karbon kaynaklı santrallerden, yenilenebilir enerji santrallerine zorunlu bir yönelim gerçekleşmiştir. Ülkemizde, yenilenebilir enerji santrallerinden, hidroelektrik ve rüzgar enerjisi konusunda kurulu güç artışının yanına son yıllarda fotovoltaik sistemler de katılmıştır. Bu çalışmada ise yaygınlığı ülkemizde hızlı bir şekilde artan çatı üstü fotovoltaik ssistemler konusu Isparta ili için ele alınmıştır. $18^{\circ}, 24^{\circ}$ ve $35^{\circ}$ yönelim açılarıyla engelebeli çatılar, $0^{\circ}$ ve $180^{\circ}$ azimut değerleri ile, düz çatılar ise yine aynı yönelim açılarında $0^{\circ}$ azimut değeri ile simüle edilerek toplamda 6 farklı simülasyon ve üç boyutlu modelleme gerçekleştirilmiştir. Simülasyon sonuçlarına bakıldığında en düşük elektrik üretim değerinin engebeli $35^{\circ}$ eğimde çatı üstü fotovoltaik sistemde, en yüksek elektrik üretim değerinin düz ve $35^{\circ}$ yönelim açısında olan çatı üstü fotovoltaik sistemde olduğu tespit edilmiştir. Bu iki çatı arasında elektrik üretim farkının da $12415 \mathrm{kWh}$ olduğu hesaplanmıştır.
\end{abstract}

Anahtar Kelimeler: Çatı Üstü Fotovoltaik Sistemler, Güneş Enerjisi Sistemleri, PVsyst

\section{Comparison of Photovoltaic Systems Designed for Different Roof Types for Isparta Province}

\begin{abstract}
Due to global warming, there has been a compulsory shift from carbon-based power plants to renewable energy power plants in electricity production. In our country, in recent years, photovoltaic power plants have joined the increase in installed power from renewable energy plants, hydroelectric and wind energy. In this study, rooftop photovoltaic power plants, the prevalence of which is increasing rapidly in our country, is discussed for Isparta Province. A total of 6 different simulations and three-dimensional modulations were carried out by simulating unobstructed roofs with azimuth values of $0^{\circ}$ and $180^{\circ}$ with $18^{\circ}, 24^{\circ}$ and $35^{\circ}$ orientation angles, and flat roofs with $0^{\circ}$ azimuth value at the same orientation angles. When the simulation results are examined, it has been determined that the lowest electricity generation value is in the rooftop photovoltaic plant with an uneven $35^{\circ}$ slope, and the highest electricity generation value is in the rooftop photovoltaic plant with a flat and $35^{\circ}$ orientation angle. It has been calculated that the electricity generation difference between these two roofs is $12415 \mathrm{kWh}$.
\end{abstract}

Keywords: Rooftop Photovoltaic Systems, Solar Energy Systems, PVsyst

\footnotetext{
* Yazarlardan Muhammet Raşit SANCAR, YÖK 100-2000 bursiyeridir.

† Sorumlu Yazar: d1840640001@,isparta.edu.tr
} 


\section{Giriş}

Sanayi devrimi sonrasında Dünya'da gerçekleșen enerji talep artışını karşılamak için elektrik üretim santrallerinde hızlı bir artış meydana gelmiştir. Hükümetler enerji talebindeki artışı karşılamak için farklı politikalar belirlemiştir. Öncelikle karbon kaynaklı yakıtlara yönelim gerçekleşmiştir. Emisyon değeri yüksek olan bu yakıtların kullanımı sonucu ortaya çıkan gazların etkisiyle küresel ısınma sorunu ortaya çıkmıştır. Küresel 1sınmanın önüne geçmek ve elektrik talebini karşılamak amacıyla yenilebilir enerji sistemlerine yönelim gerçekleşmiştir. Başlangıçta yenilenebilir enerji sistemlerinden hidroelektrik santraller yaygın olarak kullanılmaya başlanmıştır ve sonraları teknolojinin gelişimiyle rüzgâr ve güneş enerjisine yönelim hızlı bir şekilde meydana gelmiştir.

Güneş enerjisi, fotoelektrik etki prensibine dayanan fotovoltaik sistemler ve güneşin isıl enerjisinden faydalanılan isıl sistemler olarak iki ayrı kategoride incelenmektedir. Ülkemizde gerekli yasaların oluşturulması ve devlet teşvikleriyle birlikte fotovoltaik sistemler büyük bir hızla yaygınlaşmaya başlamıştır. Yapılan son çalışmalardan sonra büyük bir ivme yakalayarak ülkemizdeki kurulu güç Uluslararası Yeninelebilir Enerji Ajansı verilerine göre 2014 yılından 2015 yılına kadar 40 MW seviyesinden 249 MW değerine ulaşmış ve 2020 yılında 6667 MW seviyesine kadar yükselmiştir (IRENA, 2021). Son yıllarda kurulu güç seviyesindeki artış eskisi kadar büyük bir ivme ile gerçekleşmese de güncel olarak santral kurulumları hızlı bir şekilde devam etmektedir.

Fotovoltaik sistemler ilk yaygınlaştığı dönemlerde arazi üstü kurulumları şeklinde yapılmaktaydı. Son dönemlerde ise arazi üstü kurulumlarından çok çatı üstü sistemler şeklinde kurulumlar gerçekleşmektedir. Bir fotovoltaik sistemde başlıca kayıplar, gölgelenme, sıcaklık artışı, tozlanma gibi faktörlerdir. $\mathrm{Bu}$ faktörlerin bir santralin elektrik üretim değerlerine etkisinin önceden belirlenmesi büyük önem taşımaktadır. $\mathrm{Bu}$ sebeple, kurulumlar gerçekleşmeden önce analizler yapılmalı ve santralin projelendirilmesi konusunda en yüksek performansın hangi koşullarda elde edilebileceği belirlenmelidir. $\mathrm{Bu}$ noktada simülasyon yazılımları kullanılarak santral elektrik üretim değerlerinin önceden belirlenmesi büyük önem taşımaktadır.

Simülasyon yazılımları birçok açıdan birbirlerinden farklı özelliklere sahip olabilmektedirler. $\mathrm{Bu}$ çalışmada literatürde sıkça kullanılan simülasyon yazılımlarından PVsyst programından yararlanılmıştır. PVsyst, ilk olarak Cenevre'de tasarlanmış ve PV sisteminin çalışma ve operasyonlarının hesaplanmasına yardımcı olan bir simülasyon yazılımıdır. $\mathrm{Bu}$ yazılım, sistemin konfigürasyonunun tasarlanmasına yardımcı olması ve ayrıca üretilen enerji miktarının yaklaşık hesaplanması konusunda olanak sağlaması açısından değerlendirilmektedir. $\mathrm{Bu}$ programın altyapısında farklı meteorolojik veriler bulunur ve yapılan hesaplamalarda bu veriler kullanılmaktadır. Ayrıca bu program sistem kayıplarını detaylı bir şekilde bir kayıp diyagramı üzerinden sunmaktadır (Mermoud ve Wittmer, 2014)

$\mathrm{Bu}$ alanda yapılmış olan bir çalışmada Dicle üniversitesi bünyesinde kurulmuş olan $250 \mathrm{kWp}$ gücündeki fotovoltaik sistemin, Aralık 2015-Nisan 2016 tarihleri arasında üretim verileri alınarak bu santralin PVsyst yazılımında simülasyonu gerçekleştirilmiştir. Simülasyon sonuçları ile gerçek veriler birbirleri ile karşılaştırılmıştır (Haydaroğlu ve Gümüş, 2016). Başka bir çalışmada polisislisyum fotovoltaik paneller ile kurulan $100 \mathrm{kWp}$ gücünde şebekeye bağlı bir santralin PVsyst yazılımı ile simülasyonunu gerçekleştirmişlerdir. Santralde 323 adet $310 \mathrm{Wp}$ gücünde fotovoltaik panel kullanılmıştır. Simülasyonu yapılan santralde bir dizide 19 panel bulunmakta ayrıca, 17 adet dizi ve $20 \mathrm{~kW}$ gücünde 4 adet inverter kullanılmıştır. Simülasyon sonucunda bir yıl içerisinde 165,38 MWh dizilerden üretilen enerji ve 161,60 MWh şebekeye verilen enerji değerlerine ulaşılmıştır. Sistemin performans oranı \%80 olarak bulunmuştur (Kumar vd.,2017). Farklı bir çalışmada Fas'ın farklı bölgelerinde, mevsimsel açı ve sabit yönelim açısı elektrik üretim yönünden PVsyst yazılımı yardımıyla simüle edilerek kıyaslanmıştır. Sabit açı olarak $32^{\circ}$, mevsimsel açı olarak ise yazın $15^{\circ} \mathrm{k}$ şın ise $48^{\circ}$ kullanılmıştır. Santralde 260 Wp değerinde 3924 adet polisilisyum fotovoltaik panel, 10 adet $100 \mathrm{~kW}$ değerinde inverter kullanılmıştır. Çalışmalar sonunda verilen açılar kullanıldığında sabit yönelim açısının, mevsimsel açılardan daha yüksek performans oranına sahip olduğu tespit edilmiştir (Balmahdi ve Bouardi, 2020). $200 \mathrm{kWp}$ değerinde bir santral için Dubai konumunda PVsyst yazılımı kullanılarak bir simülasyon çalışması yapılmıştır. Santralde $285 \mathrm{Wp}$ değerinde monokristal fotovoltaik panel, 22 panelden oluşan 32 dizi ve $60 \mathrm{~kW}$ değerinde 3 adet inverter kullanılmıştır. Çalışmada mayıs ayında en yüksek enerji üretimine, aralık ayında ise en düşük enerji üretim değerine ulaşıldığı, yıllık enerji üretim değerinin 352,6 MWh olduğu ve sistemin performans oranının da \%81,7 olduğu tespit edilmiştir (Satish vd., 2020). Başka bir çalışmada $200 \mathrm{kWp}$ kurulu güce sahip bir santral için PVsyst yazılımı kullanarak simülasyon yapmış ve gerçek veriler ile Pvsyst programından alınan verileri birbirleri ile karşılaştırmışlardır. Gerçek üretim değerleri ile yazılımdan alına verilerin \%0,56 oranında farklı olduğu tespit edilmiştir (Demiryürek vd., 2020). PVsyst yazılımını kullanarak $30 \mathrm{~kW}$ kurulu güce sahip bir santral simülasyonu gerçekleştirmiş ve simülasyon sonuçlarını yorumlamışlardır (Akcan vd., 2020).

$\mathrm{Bu}$ çalışmada, Isparta ili için $240 \mathrm{~m}^{2}$ çatı alanına sahip olan bir evde şebekeye bağlı bir elektrik sistemi, PVsyst7.2 yazılımında 6 farklı çatı senaryosu ile 6 farklı simülasyon ve üç boyutlu modelleme gerçekleştirilmiş ve ülkemizde yaygınlaşan çatı üstü kurulumlar için yol gösterici olabilecek bir kaynak ortaya konulmuştur.

\section{Materyal ve Metot}

Çalışma Isparta ili için, 37,7800 enleminde, 30,5700 boylamında $997 \mathrm{~m}$ rakımda, $18^{\circ}, 24^{\circ}$ ve $35^{\circ}$ yönelim açılarına sahip çatılarda, çatı açıları ile paralel şekilde yönlendirilen fotovoltaik sistemlerin simülasyonları yapılarak gerçekleştirilmiştir. $\mathrm{Bu}$ simülasyonlarda belirlenen açılarda gölgelenmenin olduğu engebeli çatılar ve gölgelenmenin olmadığı düz çatılar için 6 ayrı analiz çalışması yapılmıştır.

Simülasyon adımlarından ilki olan panel açısı ve azimut değeri belirleme konusunda PVsyst programında "Orientation" butonu altında, Şekil 2.1'de arayüzü sunulmuş olan alandan gerekli veri girdisi yapılarak gerçekleştirilmiştir. Gölgelenmenin olduğu çatılar için azimut değeri $0^{\circ}$ ve $180^{\circ}$ belirlenmiştir. Gölgelenmenin olmadığı çatılar için ise azimut değeri $0^{\circ}$ olarak belirlenmiştir. Panellerin yönelim açıları ise çatı açılarıyla eşit bir şekilde $18^{\circ}, 24^{\circ}$ ve $35^{\circ}$ olarak belirlenmiştir.

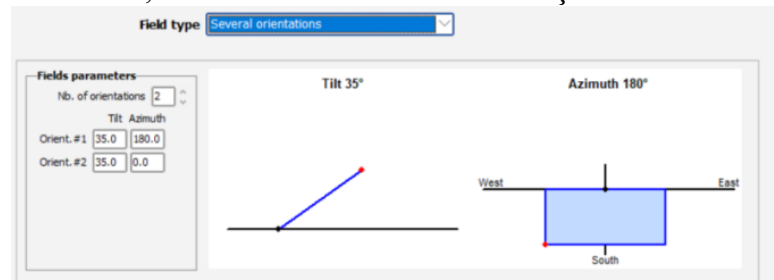

Şekil 2.1. Orientation butonu arayüzü 
Simülasyonların birbirleri ile karşılaştırılabilmesi için tüm çatı eğimlerinde ve tiplerinde panel güçleri ve türleri, panel sayıları, inverter türleri ve güçleri PVsyst yazılımının Şekil 2.2 'de System" butonu altında verilen girdi alanında tamamen aynı olacak şekilde belirlenmiştir. Tablo 2.1 'de panel inverter özellikleri verilmiştir.

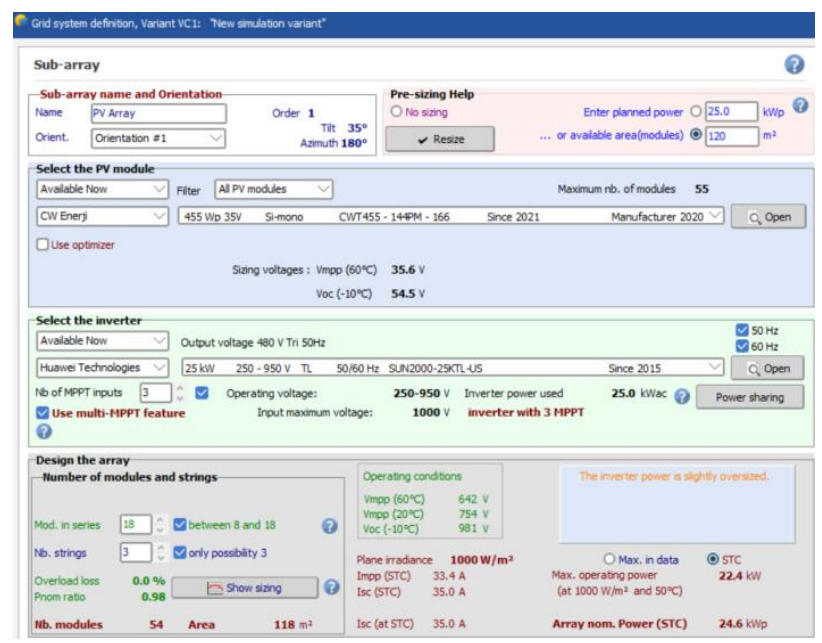

Şekil 2.2. System butonu arayüzü

Tablo 2.1. İnverter ve Panel özellikleri

\begin{tabular}{|l|l|}
\hline \multicolumn{2}{|c|}{ Fotovoltaik panel (CW ENERJI) } \\
\hline Panel Modeli & CWT455-144PM-166 \\
\hline Nominal Güç & 455 Wp \\
\hline \multicolumn{2}{|c|}{ İnverter (HUAWEI) } \\
\hline Model & SUN2000-25KTL-US \\
\hline Güç & $25 \mathrm{KW}$ \\
\hline
\end{tabular}

Sistem parametreleri Tablo 2.1'de özellikleri verilen panel ve inverterler kullanılarak belirlenmiştir. Her çatı sisteminde 108 adet panel kullanılmış, panellerden 18 'li diziler oluşturulmuş ve özellikleri verilen inverterden 2 adet kullanılmıştır. Toplam sistem kurulu gücü bütün çatılar için eşit olup 49,1 kW dır. Sistemde simülasyon yapılabilmesi için kullanılan meteroloji verilerinden PVsyst yazılımının simülasyon aracının sunduğu Meteonorm 8.0'dan yararlanılmıştır.

Çalışmada "Near Shading" butonu altında bulunan alandan sistemin üç boyutlu modellemesi gerçekleştirilmiştir. Ayrıca sistemde çatıların gölgelenmesi dışında panellerin üzerine herhangi bir gölge gelmesi çizimde ve boyutlandırmada önlenmiştir. Şekil 2.3'de engebeli ve Şekil 2.4'de düz çatılar için PVsyst yazılımı içerisinde bulunan arayüzden üç boyutlu model örnekleri sunulmuştur.

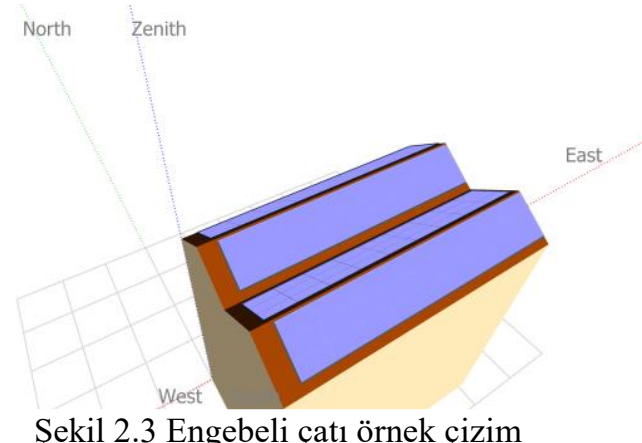

Şekil 2.3 Engebeli çatı örnek çizim

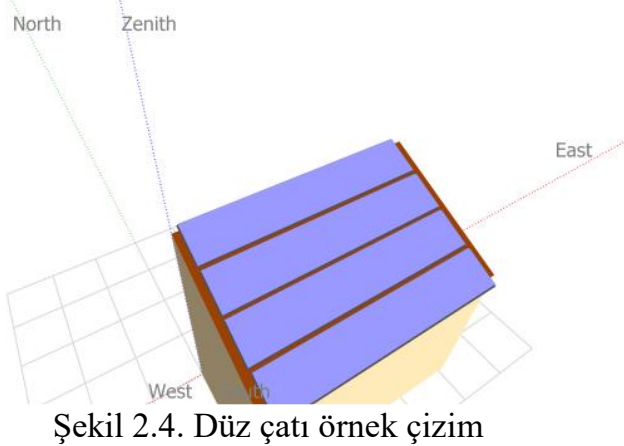

\section{Araştırma Sonuçları ve Tartışma}

Yapılan simülasyon çalışmalarından $18^{\circ}$ yönelim açısına sahip olan çatı sistemlerinden engebeli ve düz çatı sistemlerinin yıllık ortalama performans oranları Şekil 3.1 ve 3.2 'de gösterilmiştir.

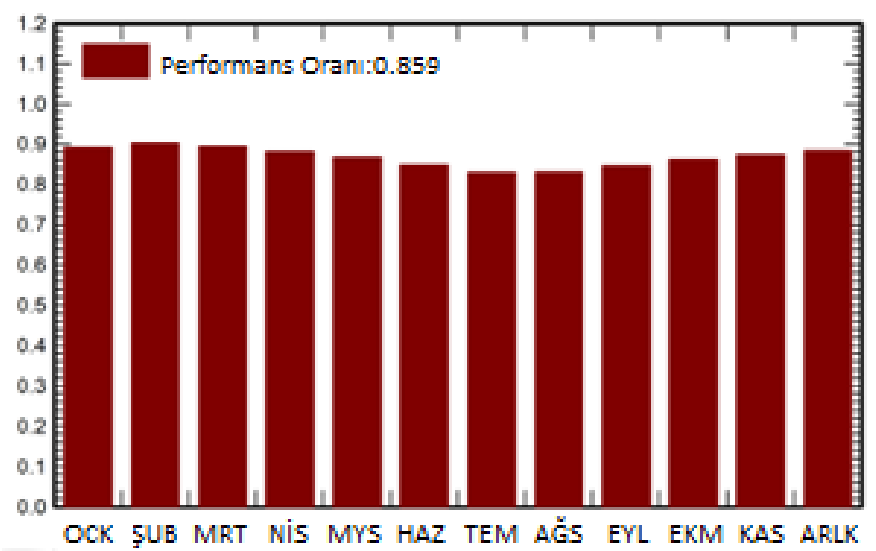

Şekil 3.1. Engebeli çatı performans oranı-18

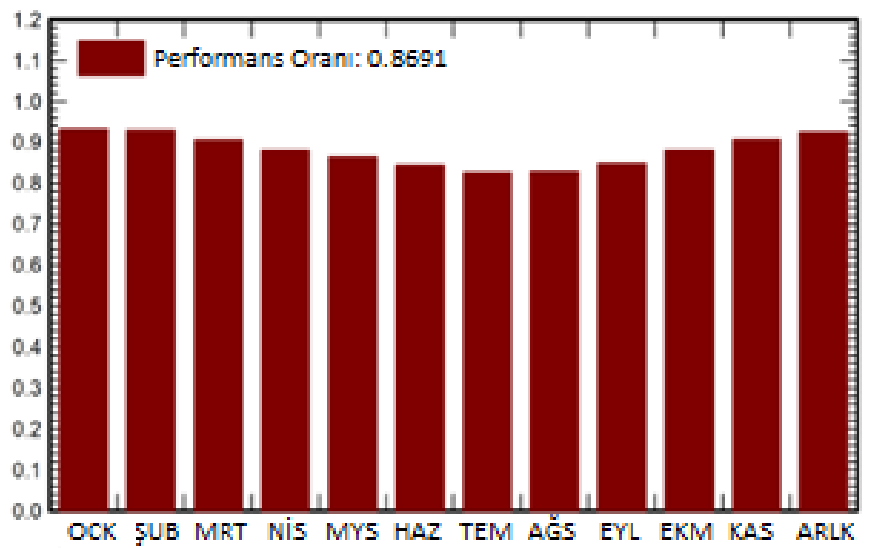

Şekil 3.2. Düz çatı performans oranı- $18^{\circ}$

Yukarıda performans oranı değerleri ile birlikte sunulan grafiklerde düz çatı için yıllık ortalama performans oranının $\% 86,9$ ve engebeli çatı için performans oranının \%85,9 değerinde olduğu görülmektedir.

Aşağıda verilen Şekil 3.3'de engebeli çatı yıllık performans oranı $24^{\circ}$ eğim için incelenmiş̧ir. Ay bazında yapılan değerlendirme sonucunda performans oranlarının, en yüksek değere 0,892 olarak şubat ayında ulaştı̆ı̆, en düşük 0,827 olarak ağustos ayında gerçekleştiği görülmektedir. $24^{\circ}$ eğimde engebeli ve düz çatıların yıllık ortalama performans oranları Şekil 3.3 ve 3.4 'de gösterilmiştir. 


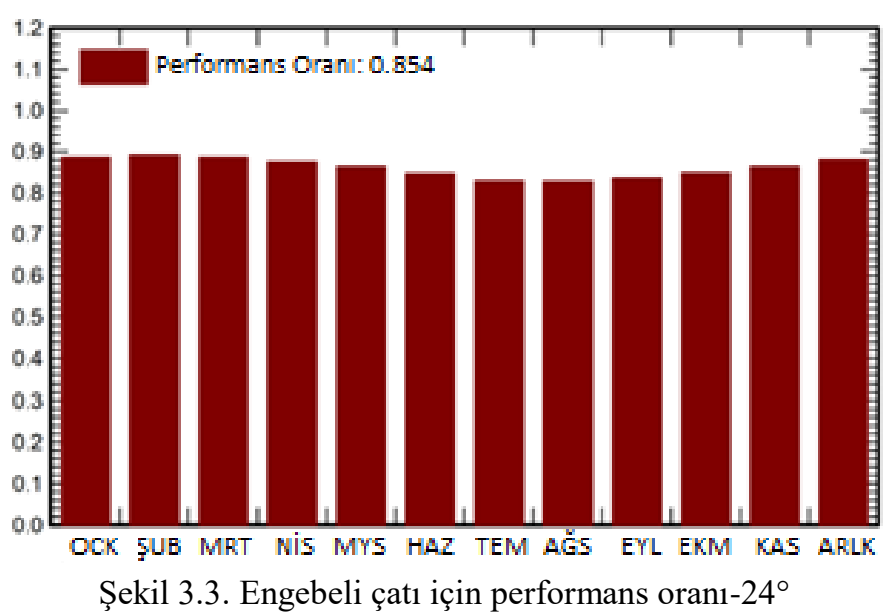

Şekil 3.4'de düz çatı performans oranı $24^{\circ}$ eğim için analiz sonuçları sunulmuştur. Burada yıllık ortalama performans oranı 0,8698 olarak gerçekleşmişken ay bazında incelendiğinde en düşük performans oranları temmuz ve ağustos aylarında görülürken, en yüksek aralık, ocak ve şubat aylarında gerçekleşmiştir.

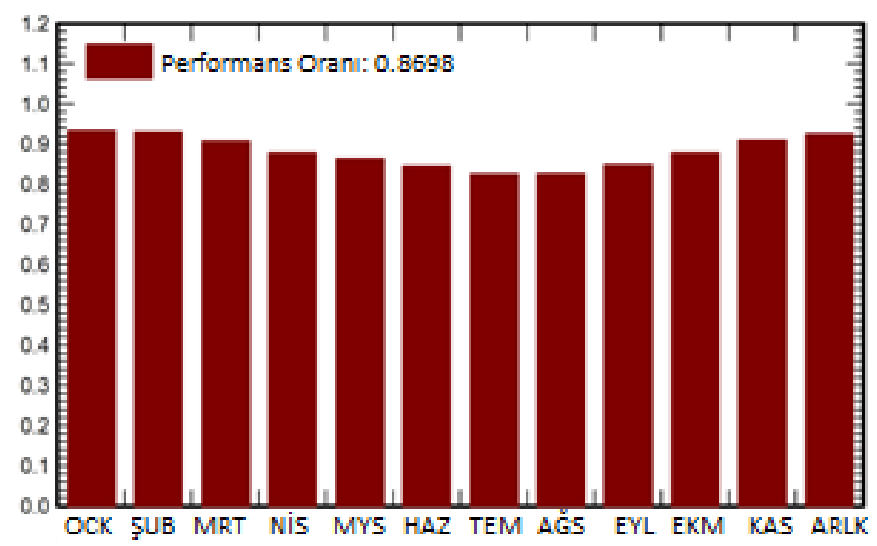

Şekil 3.4. Düz çatı performans oranı-24

$24^{\circ}$ eğimde engebeli çatı için performans oranı $\% 85,4$, düz çatı için performans oranı ise \%86,98 olarak hesaplanmıştır. $24^{\circ}$ eğimde engebeli ve düz çatıların yıllık ortalama performans oranları Şekil 3.5 ve 3.6'da gösterilmiştir.

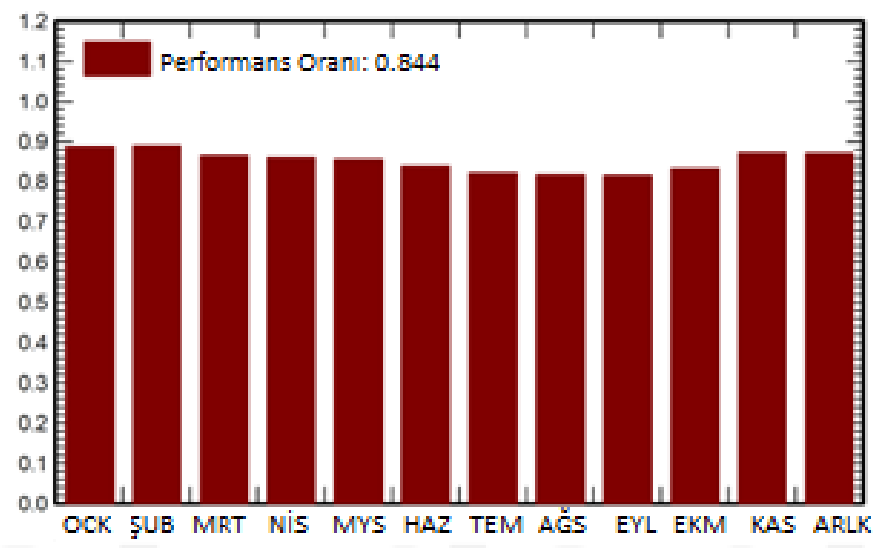

Şekil 3.5. Engebeli çatı performans oranı-35

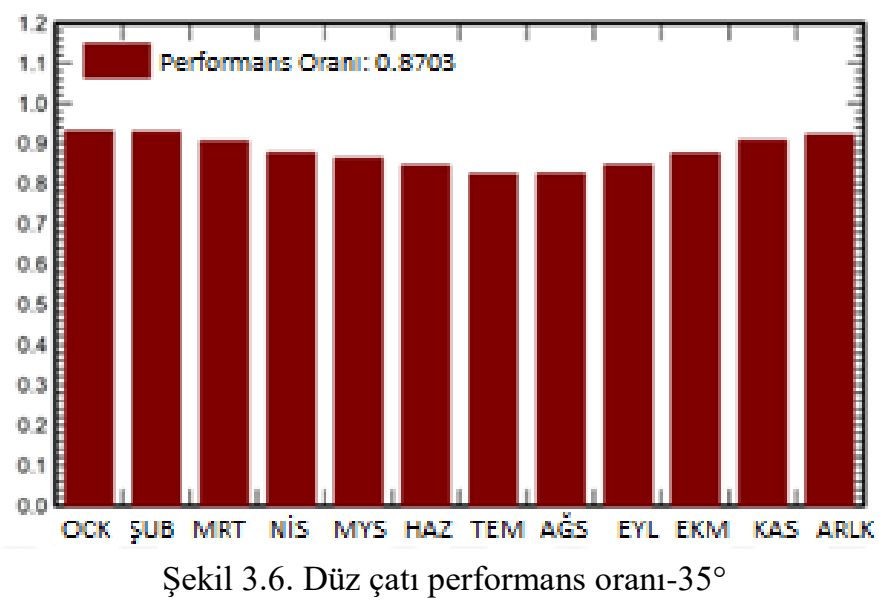

$35^{\circ}$ eğimde engebeli çatı için y1llık ortalama performans oranı $\% 84,4$, düz çatı için performans oranı ise $\% 87,03$ olarak hesaplanmıştır.

Şekil $3.7^{\prime}$ de $18^{\circ}, 24^{\circ}$ ve $35^{\circ}$ yönelim açılarında engebeli çatılar için modellenen fotovoltaik sistemlerin üretmiş olduğu enerji miktarları gösterilmiştir.

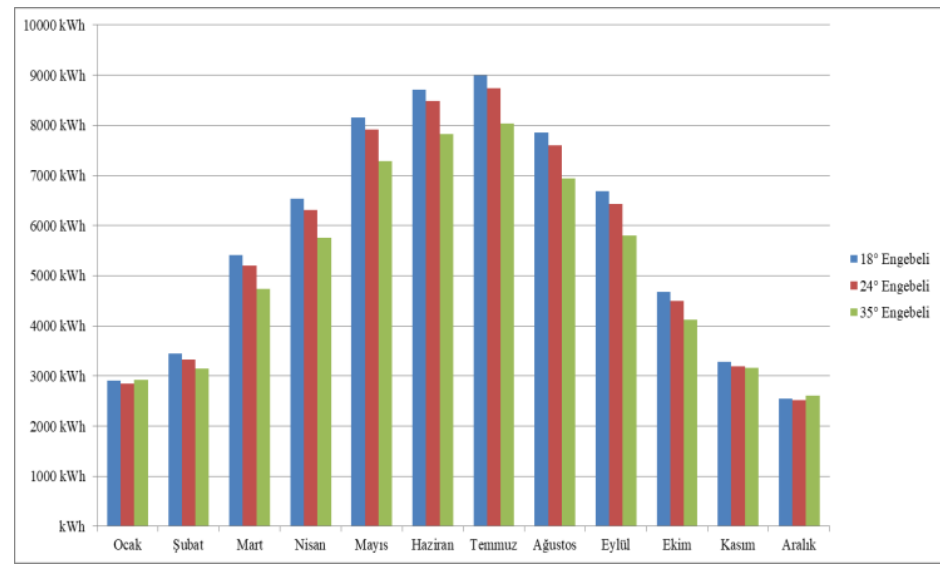

Şekil 3.7. Engebeli çatı $18^{\circ}-24^{\circ}-35^{\circ}$ için aylara göre enerji üretimleri

Şekil $3.8^{\prime}$ de $18^{\circ}, 24^{\circ}$ ve $35^{\circ}$ yönelim açılarında düz çatılar için modellenen fotovoltaik sistemlerin üretmiş olduğu enerji miktarları grafiği verilmiştir.

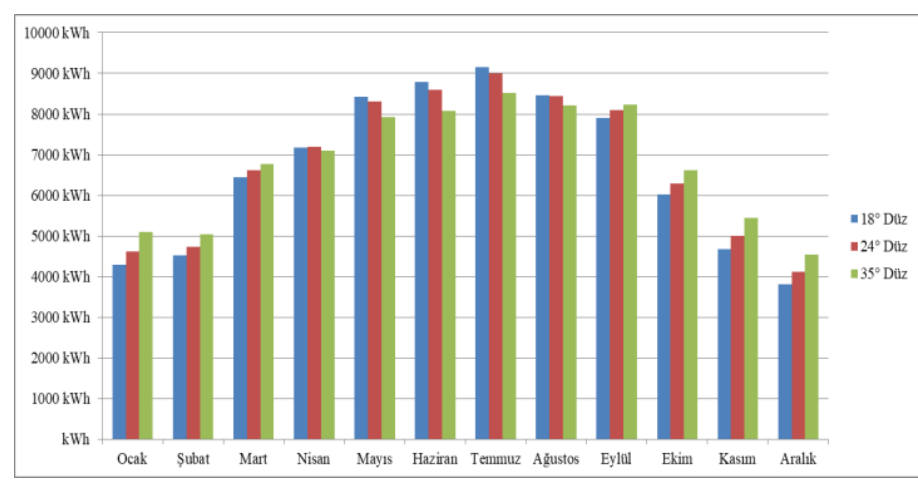

Şekil 3.8. Düz çatı $18^{\circ}-24^{\circ}-35^{\circ}$ için aylara göre enerji üretimleri

Şekil 3.9'da tüm çatı tiplerinin enerji üretim değerleri yıllık toplamlarının grafiği verilmiştir. 


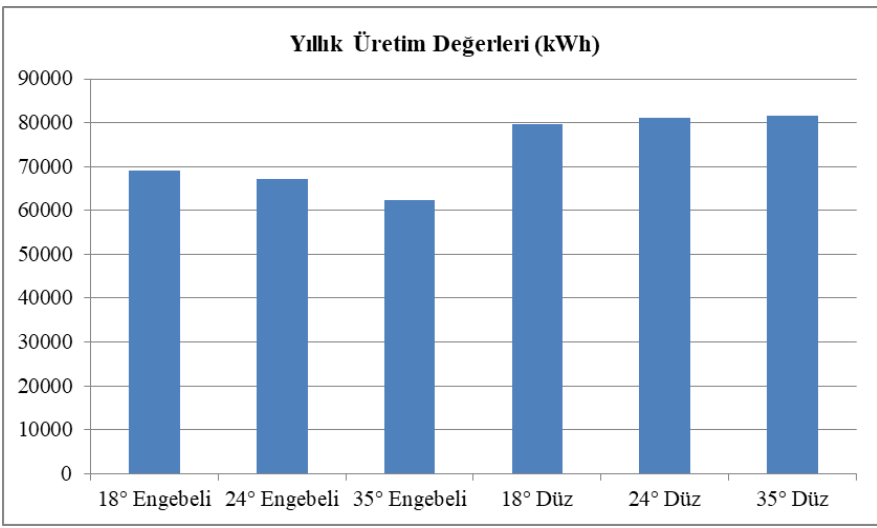

Şekil 3.9. Tüm çatı tipleri için yıllık enerji üretim değerleri

Tablo 3.1'de çatı tipleri için sıcaklık ve gölgelenme kaynaklı kayıplar sunulmuştur. En yüksek gölgelenme kaybının engebeli $35^{\circ}$ çatı tipinde gerçekleştiği ayrıca düz çatı tiplerinde sıcaklık nedeniyle gerçekleşen kayıpların daha yüksek olduğu görülmektedir.

Tablo 3.1. Çatı tipleri için gölgelenme ve sıcaklık kayıpları

\begin{tabular}{|c|c|c|c|}
\hline Çatı Tipi & Açı & $\begin{array}{c}\text { Gölgelenme } \\
(\%)\end{array}$ & Sıcaklı(\%) \\
\hline \multirow{3}{*}{ Engebeli } & $18^{\circ}$ & $0,46 \%$ & $5,84 \%$ \\
\cline { 2 - 4 } & $24^{\circ}$ & $0,93 \%$ & $5,80 \%$ \\
\cline { 2 - 4 } & $35^{\circ}$ & $1,97 \%$ & $5,57 \%$ \\
\hline \multirow{3}{*}{ Düz } & $18^{\circ}$ & $0 \%$ & $6,49 \%$ \\
\cline { 2 - 4 } & $24^{\circ}$ & $0 \%$ & $6,60 \%$ \\
\cline { 2 - 4 } & $35^{\circ}$ & $0 \%$ & $6,63 \%$ \\
\hline
\end{tabular}

Tüm çatı tipleri kontrol edildiğinde en yüksek elektrik üretim değerlerinin düz olan çatılarda gerçekleştiği bu çatılar arasından da en yüksek elektrik üretim değerinin $35^{\circ}$ yönelim açısında gerçekleşmiş olduğu görülmektedir. Yıllık ortalama performans oranları karşılaştırıldığında da en yüksek performans oranının yine düz çatı tipinde $35^{\circ}$ yönelim açısında olan fotovoltaik sistemde olduğu tespit edilmiştir. Düz çatı tiplerinde enlem derecesinin üstüne çıkılmadığından eğim arttıkça güneşten gelen enerjinin daha dik bir şekilde alınmasıyla performans oranının arttığı, bununla beraber elektrik üretim değerlerinin arttığ engebeli çatı tiplerinde ise tam tersi bir şekilde eğim arttıkça performans oranının ve dolayısıyla elektrik üretim değerlerinin azaldığı görülmektedir.

\section{Sonuç}

Gerçekleştirilen simülasyon çalışmalarına bakıldığında, enerji üretim değerleri açısından engebeli çatılarda elektrik üretim değerlerinin düşük olmasının gölgelenme faktörünün ve bunun yanında panel yüzeyine düşen 1şınım miktarında gerçekleşen azalmanın bir sonucu olarak ortaya çıktığı görülmektedir. Ayrıca sıcaklık kayıplarının elektrik üretim değerlerinin artmasıyla beraber arttığı görülmektedir.

Ülkemizde fotovoltaik sistemlerin oldukça yaygınlaştığı bu dönemde özellikle çatı üstü santrallerin kurulumunda gölgelenme faktörünün göz önünde bulundurulması ve simülasyonlarının oldukça dikkatli bir şekilde yapılması gerekmektedir. Ayrıca herhangi bir bina yapımında çatıların yönleri ve eğim açılarının özellikle güneş enerjisinden elektrik üretme noktasında önceden simülasyonlar yardımıyla belirlenmesi büyük önem arz etmektedir. Yapılan simülasyonlarda çatı tipleri birbirleriyle karşılaştırıldığında en yüksek gölgelenme oranının $35^{\circ}$ yönelim açısında engebeli çatıda gerçekleştiği ve en yüksek sıcaklık kaybının $35^{\circ}$ yönelim açısında düz çatı tipinde gerçekleştiği tespit edilmiştir. Performans oranı en yüksek olan çatı tipi $35^{\circ}$ yönelim açısına sahip düz olan çatı, en düşük performans oranına sahip olan yine $35^{\circ}$ yönelim açısında engebeli olan çatı olarak gerçekleşmiştir. En yüksek elektrik üretim değeri ve en düşük elektrik üretim değeri arasındaki fark yaklaşık olarak $12415 \mathrm{kWh}$ değerini bulmaktadır. $\mathrm{Bu}$ değer özellikle elektrik tüketimi sürekli artan ülkemizde azımsanmayacak kadar önemli bir değerdir. Bunların yanında elektrik üretim değerleri arttıkça sıcaklık kaynaklı kayıpların artması konusunda, özellikle çatı tasarımı yapılırken güneş panellerinin yerleşimi düşünülerek rüzgarla beraber doğal soğutmanın yapılabilmesi noktasında çatı tasarımında dikkat edilmesi gereken başka bir husus olarak dikkat çekmektedir.

\section{Kaynakça}

Akcan, E., Kuncan, M., \& Minaz, M. R. (2020). PVsyst yazılımı ile $30 \mathrm{kw}$ şebekeye bağl1 fotovoltaik sistemin modellenmesi ve simülasyonu.Avrupa Bilim ve Teknoloji Dergisi, (18), 248-261.

Bolat, M., Arifoğlu, U., \& Demiryürek, H. K. (2020). Lebit enerji güneş santralinin PVsyst programı ile analizi. Bitlis Eren Üniversitesi Fen Bilimleri Dergisi,9(3), 1351-1363.

Belmahdi, B., \& El Bouardi, A. (2020). Solar potential assessment using PVsyst software in the northern zone of Morocco. Procedia Manufacturing, 46, 738-745.

Haydaroğlu, C., \& Gümüş, B. (2016). Dicle Üniversitesi güneş enerjisi santralinin PVsyst ile simülasyonu ve performans parametrelerinin değerlendirilmesi. Dicle Üniversitesi Mühendislik Fakültesi Mühendislik Dergisi,7(3), 491-500.

Kumar, N. M., Kumar, M. R., Rejoice, P. R., \& Mathew, M. (2017). Performance analysis of $100 \mathrm{kWp}$ grid connected Sipoly photovoltaic system using PVsyst simulation tool. Energy Procedia,117, 180-189.

Mermoud, A., \& Wittmer, B. (2014). PVSYST user's manual. Switzerland, January.

Omar, M. A., \& Mahmoud, M. M. (2018). Grid connected PVhome systems in Palestine: A review on technical performance, effects and economic feasibility. Renewable and Sustainable Energy Reviews,82, 2490-2497.

Satish, M., Santhosh, S., \& Yadav, A. (2020). Simulation of a Dubai based $200 \mathrm{KW}$ power plant using PVsyst Software. In 2020 7th International Conference on Signal Processing and Integrated Networks (SPIN) (pp. 824-827). IEEE.

International Renewable Energy Agency (IRENA), 2016. ErişimTarihi: 28.12.2021. https://www.irena.org/solar 